\title{
Theoretical and practical studies on the metabolic engineering of Streptomyces for production of Butanols
}

\begin{abstract}
Production of biofuels is a significant technical and commercial challenge. To compete effectively with fossil fuels, the efficiency of processes that convert sustainable feedstocks to biofuel has to be improved. Ideally, the ultimate aim is a single process that degrades the renewable feedstock quickly and delivers high titers of biofuel at a price that is competitive with equivalent fuel from fossil sources. However, the microbes that are currently being investigated for biofuel production fall into two categories: those that degrade cellulosic feedstock but cannot make biofuels effectively and those that do make biofuels but are poor at degrading the cellulosic feedstock. When biofuel production is engineered into cellulose degraders, or cellulose degradation engineered into microbes with capability to produce biofuel, another factor, lignin content (a toxic component in most sustainable feedstocks), comes into play. This review considers the latent opportunity to harness Streptomyces bacteria to address this issue.
\end{abstract}

Keywords: Feedstocks, Production, Butanol, Decarbonisation, Streptomyces
Volume 5 Issue 7 - 2017

\author{
May Al Doori,' lain S Hunter ${ }^{2}$ \\ 'Oregon Institute of Technology, USA \\ ¿University of Strathclyde, UK
}

Correspondence: May Al Doori, Oregon Renewable Energy Centre, Oregon Institute of Technology, Klamath Falls, Oregon 9760I,USA, Email mayaldoori@yahoo.com

Received: December 07, 2017 | Published: December 19, 2017

\section{Introduction}

Biofuels have emerged as one of the important sustainable fuel sources and are considered as a promising way to minimize Greenhouse Gas emissions and provide new energy sources. ${ }^{1-3}$ Different countries have developed different strategies to introduce biofuels. The main concern is the economic drivers for each fuel, which varies with location and feedstocks. In addition, strategic and environmental aspects play a crucial role in the production and utilization of biofuels. ${ }^{4}$ Feedstocks, i.e. lignocelluloses, in the form of wood waste and straw are attractive alternative substrates, being available in large quantities in many geographic locations. Lignocelluloses contain carbohydrates in the form of cellulose (a polymer formed exclusively of glucose) and hemicelluloses (hetero polymers of various hexoses and pentoses in a branched structure). Invariably, they also contain lignin, a polymer of toxic aromatic compounds. ${ }^{5}$ To act as a feedstock, the cellulose and hemi-cellulose must first be digested to low molecular weight sugars, and these are fermented to alcohols (Figure 1).

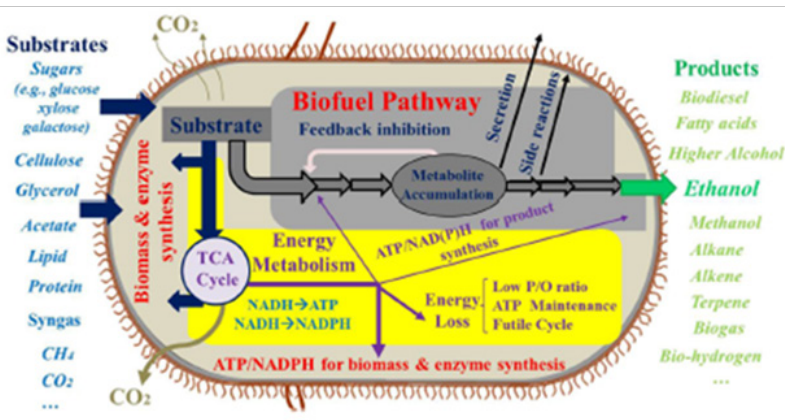

Figure I Carbon and energy limitation for biosynthesis. Reproduced from, ${ }^{12}$ with permission.

Microbes make a significant contribution to the production of biofuels. ${ }^{6,7}$ However, the yield of product by native microbes is uneconomic, which makes it necessary to develop and improve them through strategies of systems and synthetic biology. ${ }^{8,9}$ Alcohol producers, such as Saccharomyces cervisiae which are excellent at fermenting sugars to alcohols, cannot digest lignocelluloses. A combination of pretreatment ${ }^{10,11}$ of the feedstock and genetic engineering of the yeast, results in utilization of the cellulose and hemi-cellulose, but hydrolysis products of lignin are toxic to yeast. Other natural alcohol producers, e,g. the bacterium Zymomonas mobilis, have similar problems of lignin toxicity.

Therefore, the choice of organism(s) should be based on those that have a proven ability to degrade lignocelluloses, be impervious to toxicity of lignin and be comparatively fast growing. They should also be amenable to genetic manipulation and ideally have been used industrially for large scale fermentation. This mini-review considers the latent potential of Streptomyces bacteria to make a significant contribution to biofuel production, using biobutanol as an example. Although notable for antibiotic production, these resilient bacteria seem to have been overlooked in the context of biofuel production.

\section{Review of the literature and discussion}

The soil Actinomycetes are notable as being adopted by industry, particularly for large-scale production of antibiotics. Most actinomycetes do not normally produce significant quantities of alcohols. However, introduction of the key enzymes into strains can stimulate alcohol (ethanol) production. The critical enzymes are pyruvate decarboxylase and alcohol dehydrogenase. Corynebacterium glutamicum ${ }^{12,13}$ and several Streptomyces $s p .{ }^{14}$ have been manipulated successfully for ethanol production. Although ethanol has been the focus of much research in the past few decades, its shortcomings as a fuel have led to metabolic engineering of microbial hosts to produce fuels with more desirable properties such as butanol, isobutanol medium to long-chain hydrocarbons and isoprenoids. ${ }^{15,16}$ Bioethanol has been used in automobiles with gasoline in different blending proportions. ${ }^{17,18}$ However, biobutanol is considered an advanced biofuel, because of its good properties of high heat value, high hydrophobicity, reduced corrosive activity, high viscosity and low volatility. Biobutanol has great potential to be adopted in the future. ${ }^{19}$ Biological fermentative production of the advanced biofuel, 
n-butanol, was first discovered by Pasteur in 1861 and later attributed to the Gram-positive strict anaerobic bacterium, Clostridium acetobutylicum. ${ }^{20}$ Several other Clostridia species were also found to contain the acetone-butanol-ethanol (ABE) pathway ${ }^{21}$ for butanol production. Due to the requirement for anaerobic growth (resulting in slow growth), underdeveloped genetic tools and the clostridial strain being fastidious such as in spore formation, the five key reactions of the clostridial n-butanol pathway were expressed heterogeneously in Escherichia coli to develop high yielding systems. ${ }^{22,23}$ This strategy of introducing the whole pathway could also be applied to Streptomyces, for which gene manipulation methodologies is now highly developed (for example ${ }^{24}$ ). Recent strategies that have been successful for Clostridia can be applied immediately to the Streptomyces ${ }^{25}$ Finally, the production of butanol by microbes is often limited by the inherent toxicity of the butanol to the microbe - a major stumbling block in strain development in other species. It has been demonstrated that ribosome engineering in Streptomyces can confer enhanced tolerance to butanol $t$ and hence the productivity of biofuel production is not limited by its inherent toxicity to the producing organism. ${ }^{26}$

Given the complexity of the many types of biomass, biochemical conversion of plant material(s) to fuels or chemicals after pretreatment remains a complex challenge (Figure 2). Cellulose is the predominant component of sustainable feedstocks and significant progress has been made in development of assays for cellulases. ${ }^{27,28}$ To initiate the deconstruction of plant matter, a number of methods, collectively called 'Pretreatment' have been developed to initiate the breakdown process. This pretreatment step is a key process to enable efficient conversion of lignocellulosic feedstock to biofuel or other fermentation products. These methods range from alkaline, mildly acidic to strongly acidic conditions to attack of the biomass structure. ${ }^{29}$

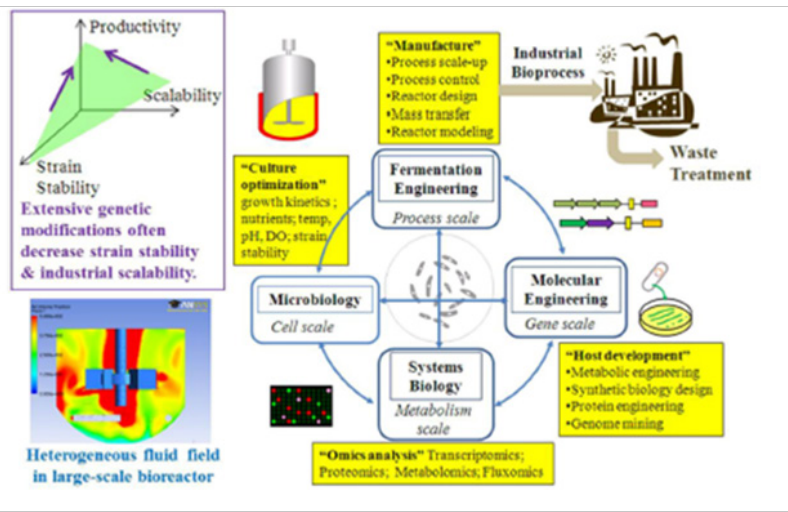

Figure 2 The design-engineering-analysis cycle for scale-up of biofuel fermentation. Reproduced from, ${ }^{12}$ with permission.

Cellulases are needed to break down the complex components of cellulosic feedstocks while also processing the pathways to ferment the resulting sugars into alcohols but there are few, if any, naturally occurring microorganisms that combine these features. One approach is therefore to introduce the key genes encoding the desired cellulolytic enzymatic activities from other species into host organisms that are already optimized for ethanol fermentation. ${ }^{30}$ Here, the natural habitat and lifestyle of Streptomyces, which is soilbased and often dependent on degradation of plant material, points to that inherent capability. The realization that some Streptomyces are prestigious at degradation of lignocelluloses ${ }^{31}$ and many have highly evolved enzymes, such as the laccases for lignin degradation, ${ }^{32}$ bodes well that Streptomyces could provide a robust organism chassis on which to build the capability to degrade lignocelluloses effectively.
To enhance that approach, genetic engineering could be used to introduce to alcohol producing microbes the metabolic pathways needed to utilize sugar sources, such as the five carbon xyloses and other pentoses that are released from hydrolysis of woody biomass. ${ }^{33}$ Much of today's commercial activity using advanced biotechnology for biofuels production processes on the 'creation; selection or improvement of strains of desired microorganisms having enhanced properties of these traits'. ${ }^{34}$

\section{Conclusion}

Production of biofuels is expected to offer new opportunities to diversify income and fuel supply sources, to promote employment in rural areas, to develop long term replacement of fossil fuels, and to reduce greenhouse gas emissions - boosting the decarbonisation of transportation fuels and increasing the security of energy supply. Biofuels contribute to lower combustion emissions than fossil fuels, per equivalent power output. They can be produced using existing technologies and be distributed through the available distribution system. For this reason, biofuels are currently pursued as a fuel alternative that can be easily applied in the short term, until other options that are harder to implement, such as hydrogen, are available. Despite biofuels being currently more expensive than fossil fuels, their production is increasing around the world.

Encouraged by policy measures and targets for use as transport fuel, global production of biofuels is estimated to be over 35 billion litres. ${ }^{35}$ Recent research efforts have concentrated on applying metabolic engineering and modern genetic methods in order to develop organisms optimized for high productivity and energy value, in order to achieve their full processing capabilities. ${ }^{36}$ It is for these reasons that Streptomyces bacteria should be considered as serious contenders for an integrated approach for production of biofuels from cellulosic feedstocks.

\section{Acknowledgements}

None.

\section{Conflicts of interest}

None.

\section{References}

1. Kim S, Dale BE. Global potential bioethanol production from wasted crops and crop residues. Biomass and Bioengineering. 2004;26(4):361-375.

2. Carere CR, Sparling R, Cicek N. Third generation biofuels via direct cellulose fermentation. Int J Mol Sci. 2008;9(7):1342-1360.

3. Zisk LH, Bunce JA, Shimono H, et al. Food security and climate change:on the potential to adopt global crop production by active selection to rising atmospheric carbon dioxide. Proc R Soc B-Biol Sci. 2012;279(1745):4079-4105.

4. Cambell CJ. The end of cheap oil Scientific American, 1998;278(3):77.

5. Stam P, Verma V, Ramamoorthy, Kumar PP. Manipulation of plant architecture to enhance lignocellulosic biomass. AoB plants. 2012;pls026.

6. Dellomonaco C, Fava F, Gonzales R. The path to next generation biofuels:success and challenges in the era of synthetic biology. Microb Cell Fact. 2010;9(3):2-15.

7. Papagianni M. Recent advances in engineering the central carbon metabolism of industrially important bacteria. Microb Cell Fact. $2012 ; 11: 50$. 
8. Peralta Yahya PP, Zang F, DelCardayre SB, et al. Microbial engineering for the production of advanced biofuels. Nature. 2012;488(7411):320-323.

9. Nevoigt E. Progress in metabolic engineering of Saccharomyces cervisiae. Microbiol Mol Biol Rev. 2008;72(3):379-412.

10. Balan V, Bals B, Shishire PS, et al. Lignocellulosic biomass pretreatment using AFEX. Methods Mol Biol. 2009;581:61-77.

11. Kim Y, Hendrickson R, Mosier NS, et al. Liquid hot water pretreatment of cellulosic biomass Methods Mol Biol. 2009;581:93-102.

12. Hollinshead WHL, Yinjie J, Tang YJ. Biofuel production:an odyssey from metabolic engineering to fermentation scale-up. Front Microbiol. 2014;5:344.

13. Inui I, Kawaguchi $\mathrm{M}$, Murakami $\mathrm{S}$, et al. Metabolic engineering of Corynebacterium glutamicum for fuel production under oxygen deprivation conditions. J Mol Microbiol Biotechnol. 2004;8(4):243-254.

14. Waltman MJ, Yang ZK, Langan P, et al. Engineering acidic Streptomyces rubiginosus D-xylose isomerase by rational enzyme design. Protein Engineering Design and Selection. 2014;27(2):59-64.

15. Swidah R, Wang H, Reid PJ, et al. Butanol production in S. cerevisiae by specific metabolic engineering and butanol resistance. Biotechnol Biofuels. 2015;8:97.

16. Gaida, SM, Leidtke A, Jentges AHW. Metabolic Engineering of Clostridium cellulolyticum for the production of $\mathrm{n}$-butanol from crystalline cellulose. Microb Cell Fact. 2016;15(6):1-11 .

17. Huffer S, Roche CM, Blanch HW, et al. Escherichia coli for biofuel production:bridging the gap from promise to practice. Trends Biotechnol. 2012;30(10):538-545.

18. Jim H, Chen L, Wang J, et al. Engineering biofuel tolerance in nonnative producing microorganisms. Biotechnol Adv. 2014;32(2):541-548.

19. Rud MA, Schrimer A. New microbial fuels:a biotech perspective. Curr Opin Microbiol. 2009;12(3):274-281.

20. Gabriel C. Butanol fermentation process. Ind Eng Chem. 1928;20(10):1063-1067.

21. Jones DT, Woods DR (1986) Acetone-Butanol -Fermentation revisited Microbiol Rev. 1986;50:484-524.

22. Sticklen MB. Plant genetic engineering for biofuel production:towards affordable cellulosic ethanol. Nat Rev Genet. 2008;9(6):433-443.

23. Sakuragi H, Kuroda K, Ueda M. Molecular breeding of advanced microorganisms for biofuel production. $J$ Biomedicine and Biotechnology. 2011;416931:11
24. Sevillano L, Vijgenboom E, van Wezel GP, et al. New approaches to achieve high level enzyme production in Streptomyces lividans. Microb Cell Fact. 2016;15:28.

25. Schwarz KM, Grosse-Honebrink A, Derecka K, et al. Towards improved butanol production through targeted genetic modification of Clostridium pasteurianum. Metab Eng. 2017;40:24-137.

26. Tanaka Y, Kasahara K, Hirose Y, et al. Enhancement of butanol production by sequential introduction of mutations conferring butanol tolerance and streptomycin resistance. Bio sci Bioeng. 2017;124(4):400-407.

27. Sanchez OJ, Cardona CA. Trends in biotechnological production of fuel ethanol from different feedstocks. Bioresour Technol. 2008;99(13):5270-5295.

28. Wilson DB. Microbial diversity of cellulose hydrolysis. Curr Opin Microbiol. 2011;14(3):259-263.

29. Wyman CE, Dale B, Elander RT, et al. Coordinated development of leading biomass pretreatment technologies. Biores Technol. 2005;96(18):1959-1966.

30. Aldoori M, Murthy G, Hunter IS. Progress in biofuels production from renewable resources. Progress in Energy and Combustion Science. 2017;37(1):52-68.

31. Feng H, Sun Y, Zhi Y, et al. Lignocellulose degradation by the isolate of Streptomyces griseorubens JSD-1. Funct Integr Genomics. 2015;15(2):163-173

32. Majumdar S, Lukk T, Solbiati JO, et al. Roles of Small Laccases from Streptomyces in Lignin Degradation. Biochemistry. 2014;53(24):4047-4058.

33. Kumar D, Murthy GS. Stochastic molecular model of enzymatic hydrolysis of cellulose for ethanol production. Biotechnol Biofuels. 2013;6(1):63.

34. Naik SN, Goud VV, Rout PK, et al. Production of first and second generation biofuels: a comprehensive review. Renewable and Sustainable Energy Reviews. 2010;14(2):578-597.

35. Rao A, Sathiavelu A, Mythili S. Genetic Engineering in BioButanol Production and Tolerance. Braz arch biol technol. 2016;59:1678-4324.

36. Pfromm PH, Amanoar-Boadu V, Nelson R, et al. Bio-butanol vs.Bioethanol:a technical and economic assessment for corn and switchgrass fermented by yeast or Clostridium acetobutylicum. Biomass \& Bioenergy. 2010;34(4):515-524. 